University of Nebraska - Lincoln

DigitalCommons@University of Nebraska - Lincoln

Timothy J. Gay Publications

Research Papers in Physics and Astronomy

October 1999

\title{
A simplified GaAs polarized electron source
}

H. M. Al-Khateeb

University of Nebraska - Lincoln

B. G. Birdsey

University of Nebraska - Lincoln

T. C. Bowen

University of Nebraska - Lincoln

A. S. Green

University of Nebraska - Lincoln

M. E. Johnston

University of Nebraska - Lincoln

See next page for additional authors

Follow this and additional works at: https://digitalcommons.unl.edu/physicsgay

Part of the Physics Commons

Al-Khateeb, H. M.; Birdsey, B. G.; Bowen, T. C.; Green, A. S.; Johnston, M. E.; and Gay, Timothy J. , "A simplified GaAs polarized electron source" (1999). Timothy J. Gay Publications. 43.

https://digitalcommons.unl.edu/physicsgay/43

This Article is brought to you for free and open access by the Research Papers in Physics and Astronomy at DigitalCommons@University of Nebraska - Lincoln. It has been accepted for inclusion in Timothy J. Gay Publications by an authorized administrator of DigitalCommons@University of Nebraska - Lincoln. 


\section{Authors}

H. M. Al-Khateeb, B. G. Birdsey, T. C. Bowen, A. S. Green, M. E. Johnston, and Timothy J. Gay 


\title{
A simplified GaAs polarized electron source
}

\author{
H. M. Al-Khateeb, B. G. Birdsey, T. C. Bowen, ${ }^{\text {a) }}$ A. S. Green, M. E. Johnston,, \\ and T. J. Gay \\ Behlen Laboratory of Physics, University of Nebraska, Lincoln, Nebraska 68588-0111
}

(Received 2 March 1999; accepted for publication 9 July 1999)

\begin{abstract}
We report operational and construction details of a simplified GaAs polarized electron source. It is contained in a modified $4.63 \mathrm{in}$. Conflat four-way cross, and uses a single $56 \mathrm{\ell} / \mathrm{s}$ turbomolecular pump. The design incorporates multiple cesiators to extend source lifetime, a new spring-clamp GaAs crystal mounting design to provide uniform crystal heating, and a very simple tubular $90^{\circ}$ electrostatic deflector. We also discuss matters related to preparing, heat cleaning, and activating the GaAs crystal. (C) 1999 American Institute of Physics. [S0034-6748(99)04010-1]
\end{abstract}

\section{INTRODUCTION}

In the mid-1970's Pierce, Meier, and Zurcher reported the development of an intense source of polarized electrons based on photoemission from $p$-type GaAs. ${ }^{1}$ Alternating layers of cesium and oxygen on the crystal surface were used to give it a negative electron affinity (NEA) and subsequent high quantum efficiency. ${ }^{2}$ In the last two decades, the use of GaAs sources has become widespread in many areas of research, ${ }^{3}$ mainly because of the following advantageous features: narrow energy spread, high brightness, favorable figure of merit (polarization squared times electron current), and the possibility of reversing electron polarization optically without changing the beam characteristics. However, the source is not without disadvantages: cleaning and activating the crystal are time consuming processes; and an ultrahigh vacuum free of contaminants is required. Since the invention of the GaAs source of polarized electrons, much research has been done to reduce or eliminate these problems. ${ }^{4,5}$ In this article, we discuss a source of very simple, compact design. Furthermore, we comment on the preparation and activation of the crystal. Our conclusions are based on more than three years of operating experience with the source.

\section{DETAILS OF THE SOURCE}

Our source chamber is a commercially available $4.63 \mathrm{in}$. Conflat four-way cross which has been modified with two additional 2.75 in. half nipples as shown in Fig. 1. We added an extra double-sided flange to the upstream end of the chamber during a modification of our source. It is used as a spacer to keep the crystal positioned directly below the laser window. A second double-sided flange on the downstream end is used to support electrostatic lenses. The GaAs sample and its holder are removed from the chamber by opening the upstream set of flanges. The 4.63 in. flange below the plane of the diagram is connected to the turbopump; the opposite

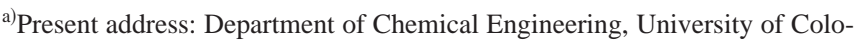
rado, Boulder, CO 80309.

b) Present address: Department of Physics, University of Saint Thomas, 2115 Summit Ave., St. Paul, MN 55105-1096.
}

flange above the diagram plane supports the oxygen inlet and cesium dispensers. A 2.75 in. half-nipple added to the top of the chamber is used for a laser window and as a support for the laser optical train. The bottom nipple, also added to the cross, holds a residual gas analyzer or ionization gauge. We use a $56 \mathrm{l} / \mathrm{s}$ turbomolecular pump (Pfeiffer Model TMU 065) instead of an ion pump because many of our experiments result in a relatively high partial pressure of noble gases in the source chamber. Moreover, bakeout procedures and initial pumpdown from atmosphere are much easier with a turbopump. The vacuum system typically achieves a base pressure of about $3 \times 10^{-10}$ Torr after baking for 4-6 days at $150^{\circ} \mathrm{C}$. All components contained in the source chamber are made from Macor, aluminum, copper, or nonmagnetic stainless steel. We have found that a molecular drag stage on the turbopump or, alternately, a turbo or diffusion pump backing the main turbopump is necessary to achieve base pressures adequate to allow crystal activation. This requirement appears to be due to the low compression ratios for $\mathrm{H}$ and $\mathrm{He}$ typical of standard turbopumps.

In our source we use bulk $\langle 100\rangle p$-type GaAs crystals that are $\mathrm{Zn}$ doped to provide a carrier concentration of about $2.0 \times 10^{19} \mathrm{~cm}^{-3}$. The wafers, purchased from Crystal Specialties, Inc., have a thickness of $0.25 \mathrm{~mm}$ and we cut them in rectangular pieces with dimensions of $0.4 \times 1.2 \mathrm{~cm}$. Inside the vacuum system a crystal piece is clamped between two adjacent tungsten springs that we wind from 0.07 in. diameter wire. The springs are screwed onto two 2-56 stainless steel threaded rods as shown in Fig. 2. We have found that this design protects the crystal from cracking during the mounting procedure and provides the good electrical contact necessary for uniform heat cleaning. These springs need to be replaced each time we change the crystal because the high temperature from the cleaning makes them brittle.

Before installing the GaAs wafers in the source, we chemically clean them using the procedure discussed in Ref. 6. After being checked for electrical continuity, the mounted crystal is placed in the vacuum chamber within $30 \mathrm{~min}$, and the chamber is pumped down to about $10^{-7}$ Torr. At this point, all the cesium dispensers ${ }^{7}$ are outgassed by resistive heating at $3.8 \mathrm{~A}$ for $30 \mathrm{~min}$ and the GaAs crystal is then also outgassed. The heating current through the crystal is in- 


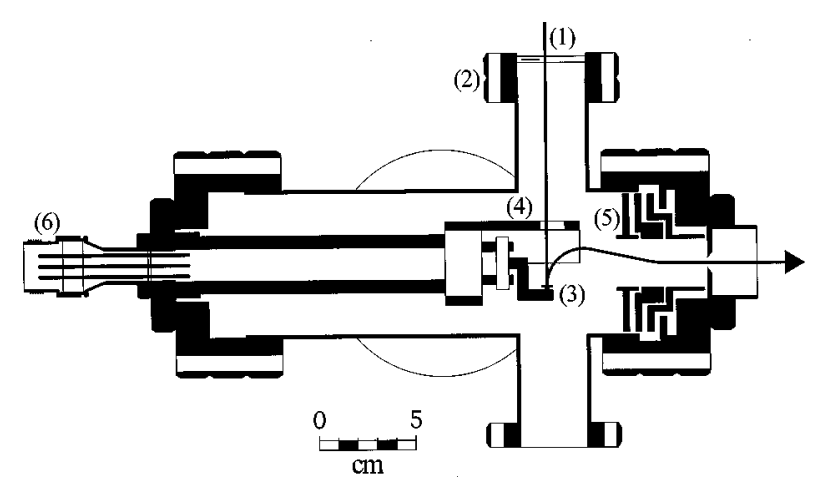

FIG. 1. Side view of the GaAs source chamber: (1) laser beam; (2) laser beam entrance window; (3) GaAs crystal; (4) cylindrical spin rotator; (5) electrostatic lenses; (6) electrical feedthrough.

creased in 0.2 A steps every 10 min until a maximum current of 1.3-1.4 A is reached. The current is held constant for 30 min before being stepped back to zero. This ohmic heating ensures that the crystal is the hottest object in the chamber (thereby minimizing deposition of contaminants on the surface) and provides a fairly uniform temperature across the usable surface of the crystal. This uniformity is improved by using a $60 \mathrm{~Hz}$ alternating heater current. After the crystal and cesium dispensers have been outgassed the source chamber is baked out.

\section{GaAs ACTIVATION}

After the bakeout, the crystal must be "activated" to produce a NEA surface. The activation procedure consists of heat cleaning, cooling to room temperature, and then, using the procedure outlined in Ref. 6, applying $\mathrm{Cs}$ and $\mathrm{O}_{2}$. The heat cleaning temperature cannot exceed $660^{\circ} \mathrm{C}$ or As will evaporate nonstochiometrically from the surface, making final activation impossible. It is easy to tell if this temperature limit has been exceeded because the crystal develops a frosty appearance, in contrast with its normal mirror-smooth surface. With practice, the red-orange color temperature just below this point can be gauged by eye, without resort to more quantitative thermometers. "Practice" in this regard, consists of heat cleaning the crystal with a first current just sufficient to cause a dull red glow, allowing it to cool, and then attempting to activate it with $\mathrm{Cs}$ and $\mathrm{O}_{2}$. If activation is

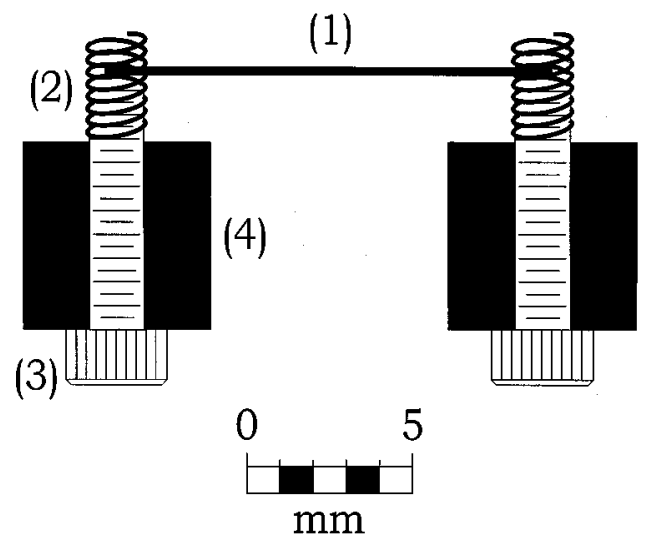

FIG. 2. End view of the crystal holders: (1) GaAs crystal; (2) tungsten springs screwed over stainless steel bolts (3); (4) stainless-steel blocks.

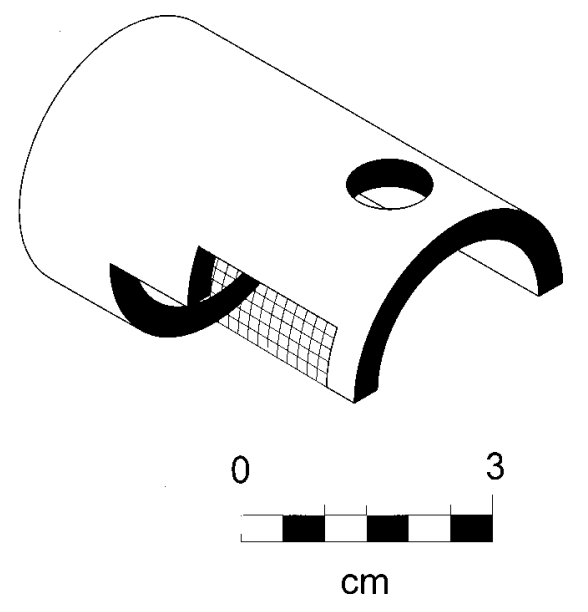

FIG. 3. Isometric view of the $90^{\circ}$ electrostatic deflector.

not achieved, the process is repeated with a higher current until a good quantum efficiency is obtained, or the crystal is destroyed. A novice will typically kill two or three crystals before being able to produce a good photocathode. The crystal is held at maximum temperature between 0.5 and 5 hours before cooling. The longer times are used when good quantum efficiencies cannot be obtained with a $0.5 \mathrm{~h}$ heating time, even with a good color temperature.

Oxygen used during the activation process is "ultrahigh purity" (99.998\%) and flows into the vacuum chamber through a Granville Phillips Model 203 variable leak valve. Commercially available cesium dispensers ${ }^{7}$ are used for activation. For photoemission, we use a $40 \mathrm{~mW}$ diode laser $^{8}$ with wavelength $780 \mathrm{~nm}$ which illuminates the crystal through a hole in the $90^{\circ}$ electrostatic deflector (see Fig. 3). With this laser, we measure photocurrents from the NEA crystal typically between 10 and $40 \mu \mathrm{A}$. This corresponds to a quantum efficiency $(\mathrm{QE})$ of $0.05 \%-0.20 \%$. After the crystal has been activated, we maintain the initial QE with a small Cs flux from the dispensers, which are aimed directly at the crystal surface about $5 \mathrm{~cm}$ away. This requires a steady-state current of about $4 \mathrm{~A}$ through the cesiators. When the gate valve separating the source from the rest of the experiment is opened, the Cs flux must be increased to keep the photocurrent constant. Under these conditions, an activation will last between four and six days, depending on the target gas and pressure being used.

A new GaAs crystal in a freshly baked chamber generally needs several activations before giving a stable and high intensity photocurrent. The reason for this may be that the crystal becomes cleaner after each heat cleaning, and the surfaces inside the chamber become coated with cesium which acts as a getter. To maximize the time between cesiator replacements, we put four of them in the source chamber. (We are currently designing a new flange that holds 10 cesiators). In our experience, there are rough correlations between the type of source pump used and/or the source size with the ease of crystal activation and the rate at which Cs must be sprayed on the crystal in the steady state. Specifically, larger source chambers $(\sim 30 \ell)$ pumped with iongetter pumps have required a much lower level of cesiation than that used in the present chamber $(\sim 2 \emptyset)$ pumped by a 


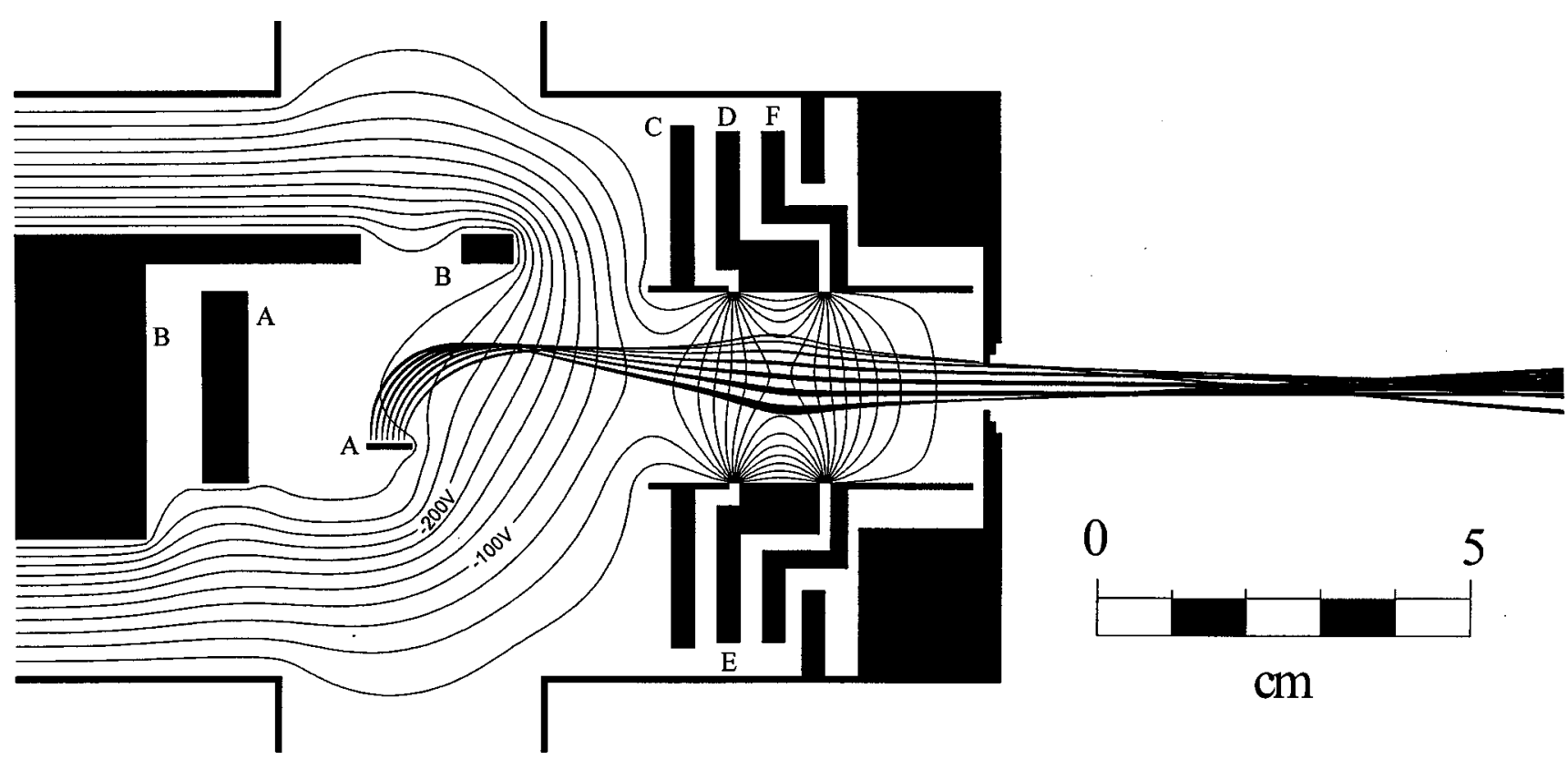

FIG. 4. Scale diagram of the electrostatic elements inside the source chamber. They have the following voltages: (A) at $-263 \mathrm{~V},(\mathrm{~B})$ at $-320 \mathrm{~V},(\mathrm{C})$ at $0 \mathrm{~V}$, (D) at $-188 \mathrm{~V},(\mathrm{E})$ at $-220 \mathrm{~V}$, and $(\mathrm{F})$ at $-256 \mathrm{~V}$. A number of electron trajectories resulting from these voltages calculated by SIMION (Ref. 11) are also shown. Space charge effects are ignored. A $4.7 \mathrm{~mm}$ diameter aperture separates the source and differential pumping chambers. Thin curves are the equipotential lines surrounding the crystal, $90^{\circ}$ deflector, and other electrostatic lenses.

turbopump. Crystal activation is also easier with the $30 \ell$ source. A $10 \ell$ source we use on another experiment, which is pumped by a magnetically levitated turbopump removed $0.5 \mathrm{~m}$ from the source chamber has performance characteristics midway between those of the 2 and $30 \ell$ sources. We speculate that this is related in part to the difference in typical chamber base pressures: $2 \times 10^{-11}$ Torr with ion pumps versus $3 \times 10^{-10}$ Torr for our present source and $1 \times 10^{-10}$ Torr for the $10 \ell$ source. We note that the group of Professor Reichert in Mainz has built a source using an ion-pumped 2.75 in. Conflat four-way cross that has good performance. ${ }^{9}$ They attribute the long lifetime of their crystal activations to the fact their experimental targets are alkali metals, which would diffuse into the source chamber and continuously rejuvenate the crystal surface.

\section{ELECTRON BEAM CHARACTERISTICS}

To produce a transversely polarized electron beam, we use a particularly simple electrostatic $90^{\circ}$ deflector above the crystal to change the electron momenta without affecting their spin directions. ${ }^{10}$ This deflector, shown in Fig. 3, is a simple stainless steel cylinder cut in half lengthwise with a hole in the top for the laser beam. On the side of the deflector nearest the cesiators is a notch covered by copper screen to "smooth" the electric field lines while letting cesium vapor reach the crystal. Aquadag ${ }^{11}$ is used to attach the copper screen to the bender. Figure 1 shows this deflector and the electrostatic lenses used to tune the electron beam toward the target cell. These lenses are machined from aluminum and coated with Aerodag (a spray form of Aquadag) to absorb stray electrons, eliminate charging, and minimize patch effects. We have found the aluminum/Aerodag combination to be UHV compatible and a completely suitable replacement for stainless steel, molybdenum, or copper electrodes. A viton-sealed (copper bonnet seal) gate valve and a differential pumping chamber isolate the target and source chambers.

Figure 4 shows a simulation of electrostatic lens steering and focusing action on an ensemble of typical electron trajectories using SIMION 6.0. ${ }^{12}$ This program is able to take into account the deviation from cylindrical symmetry of the crystal mount and $90^{\circ}$ bender. We note that despite the bender's crude design, it provides two-dimensional focusing of the extracted beam. Vertical focusing is evident in Fig. 4. The transport efficiency of the electron beam from the crystal to a $1 \mathrm{~mm}$ diameter circular-entrance aperture at the target, about $60 \mathrm{~cm}$ downstream, is greater than $30 \%$. Using a noble-gas optical polarimeter, ${ }^{13}$ we measure the polarization of our source to be $28(3) \%$, which is consistent with earlier measurements we have made using bulk GaAs crystals. The energy width of the beam, determined by observing fluorescence of the $3^{3} D \rightarrow 2^{3} P$ transition in He in the vicinity of the $\mathrm{He}^{-}\left({ }^{2} D\right)$ resonance ${ }^{14}$ is typically $0.25 \mathrm{eV}$ full width at half maximum (FWHM). However, the width varies between 0.15 and $0.35 \mathrm{eV}$, depending on the size of the laser spot and the position of the spot centroid on the GaAs crystal. It does not, in contrast with the results of the other investigations, ${ }^{15}$ appear to vary significantly with extracted current below 10 $\mu \mathrm{A}$.

\section{ACKNOWLEDGMENTS}

This work was supported by the National Science Foundation under Grant No. PHY-9732258. The authors would like to acknowledge the excellent work of the mechanical workshop staff in the UNL Physics Department.

\footnotetext{
${ }^{1}$ D. T. Pierce, F. Meier, and P. Zurcher, Phys. Lett. A 51, 465 (1975).

${ }^{2}$ R. L. Bell and W. E. Spicer, Proc. IEEE 58, 1788 (1970).

${ }^{3}$ J. Kessler, Polarized Electrons, 2nd ed. (Springer, Berlin, 1985).
} 
${ }^{4}$ Spin 96, Proceedings of the Twelfth International Symposium on HighEnergy Spin Physics, 1996, Amsterdam, The Netherlands, edited by C. W. de Jager, T. J. Ketel, P. J. Mulders, J. E. J. Oberski, and M. OskamTamboezer (World Scientific, Singapore, 1997).

${ }^{5}$ Proceedings of the Workshop on Photocathodes for Polarized Electron Sources for Accelerators, Stanford Linear Accelerator Center, Stanford, CA, 1993 (SLAC Publication 432 Rev. April 1994).

${ }^{6}$ D. T. Pierce, R. J. Celotta, G. C. Wang, W. N. Unertl, A. Galejs, C. E. Kuyatt, and S. R. Mielczarek, Rev. Sci. Instrum. 51, 478 (1980).

${ }^{7}$ Model CS/NF/3.9/12/t14+14 (Purchased from SAES Getters, Colorado Springs, CO 80906).

${ }^{8}$ Model DLS-500-780-50 (Purchased from Lasiris Inc., 3549 Ashby, St. Laurent, Quebec, Canada).

${ }^{9}$ N. Ludwig, A. Bauch, P. Nass, E. Reichert, and W. Welker, Z. Phys. D 4,
177 (1986); see also P. Nass, Diplomarbeit thesis, Universität Mainz, 1982.

${ }^{10}$ See, for comparison, the deflector of Ref. 6 or that described by K. Jost, J. Phys. E 12, 1006 (1979).

${ }^{11}$ Acheson Colloids Company, Port Huron, MI 48060. Aquadag instead of Aerodag is used to attach copper screen to the bender to avoid clogging the screen with carbon.

${ }^{12}$ D. A. Dahl, simion 3D, Version 6.0 (1995), Idaho Technologies Company, Idaho Falls, ID 83415

${ }^{13}$ T. J. Gay, J. E. Furst, K. W. Trantham, and W. M. K. P. Wijayaratna, Phys. Rev. A 53, 1623 (1996).

${ }^{14}$ H. Batelaan, J. Van Eck, and H. G. M. Heideman, J. Phys. B 24, L397 (1991).

${ }^{15}$ U. Kolac, M. Donath, K. Ertl, H. Lebl, and V. Dose, Rev. Sci. Instrum. 59, 1933 (1988) 